\title{
Evaluation of Risk Factors for Pediatric Cancers in the West of Iran
}

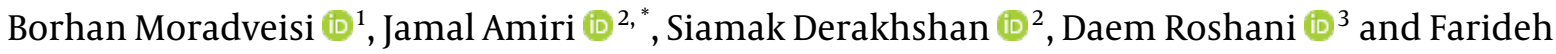 \\ Elahimanesh (10) ${ }^{4}$ \\ ${ }^{1}$ Cancer and Immunology Research Center, Kurdistan University of Medical Sciences, Sanandaj, Iran \\ ${ }^{2}$ Department of Radiotherapy, Faculty of Paramedical Sciences, Kurdistan University of Medical Sciences, Sanandaj, Iran \\ ${ }^{3}$ Social Determinants of Health Research Center, Research Institute for Health Development, Kurdistan University of Medical Sciences, Sanandaj, Iran \\ ${ }^{4}$ Department of Radiology, Faculty of Paramedical Sciences, Kurdistan University of Medical Sciences, Sanandaj, Iran \\ "Corresponding author: Department of Radiotherapy, Faculty of Paramedical Sciences, Kurdistan University of Medical Sciences, Sanandaj, Iran. Email: \\ amirijamal123@gmail.com
}

Received 2021 February 02; Revised 2021 May 23; Accepted 2021 May 24.

\begin{abstract}
Background: Occurrence of pediatric cancers is affected by maternal, environmental, and hereditary/genetic factors.

Objectives: The purpose of this study was to evaluate the correlation between background radiation, ultrasound and other possible risk factors for pediatric cancers incidence indicators.

Methods: In a cross-sectional study during 2 years, 103 patients under 14 years were studied. A total of 13 environmental, maternal and hereditary/genetic risk factors were studied, and the study was performed by using a questionnaire, measurement of background radiation, and statistical data. Incidence in the studied sample size at city (ISSSC) and incidence in the studied sample size at area (ISSSA) indicators were defined.

Results: The mean age of patients was $(6.31 \pm 3.22)$ including 54 (52.4\%) males and 49 (47.6\%) females. History of repeated ultrasound before gender determination (RUBGD) and repeated ultrasound during pregnancy (RUDP) were statistically higher in solid tumors group. Toxic substances (TS) and pediatric medical ionizing radiation (PMIR) was higher in hematologic malignancies. Statistically significant association were found between of cancer types and Family history of leukemia (FHL), Family history of solid tumors (FHST), Abortion history (AH), Maternal smoking during pregnancy (MSDP), Children's residence place (CRP), and background radiation (BR) variables. No statistically significant association was found between cancer types and maternal pregnancy age (MPA), IVF baby, and maternal ionizing radiation exposure (MIRE) variables.

Conclusions: Pediatric cancers are multifactorial diseases. Increased background radiation is correlated with an increased incidence of all pediatric malignancies. It seems that increasing ultrasound scans might increase the risk of solid tumors in children.
\end{abstract}

Keywords: Pediatric Cancers, Radiation, Risk Factors, Ultrasound

\section{Background}

Occurrence of pediatric cancers is affected by maternal, environmental, and hereditary-genetic factors $(1,2)$. Maternal factors include smoking and pregnancy age. Environmental factors include background radiation, medical radiation, direct or indirect exposure to toxic or unusual substances, etc. Hereditary and genetic factors include a family history of solid tumors, family history of blood malignancies, etc. (3-5). Cancers are generally divided into hematologic malignancies including acute lymphocytic leukemia (ALL), acute myeloid leukemia (AML), chronic myeloid leukemia (CML), and chronic lymphocytic leukemia (CLL) and solid tumors, such as brain tumors, sarcomas, Wilms' tumor, germ cell tumors, and malignant liver tumors. ALL, AML, and CML are more common in children $(6,7)$. Cell sensitivity to radiation depends on the rate of cell metabolism and cell proliferation (8).

Background radiation originates from cosmic rays and the earth's surface radioactive materials (terrestrial radiation). Cosmic rays are found almost all over the surface of the earth, but they are further in high-altitude areas (9). Terrestrial radiation originates from natural decay series such as uranium, plutonium, and actinium. The amount of radiation from these sources depends on the amount of their accumulation in each location (10). Background radiation is different in various regions (11). Radon gas is one of the terrestrial elements of the uranium series that can diffuse out of the ground, and its radiation could be greatly increased in basements of buildings (12).

The cumulative annual dose rate is total radiation from terrestrial elements gamma rays, radon gas, food radionuclides, and cosmic radiation. Fifteen percent of pediatric 
leukemia (except for CLL) could be induced by background radiation (13). There is an association between background radiation and the risk of various types of leukemia and nervous system tumors (14).

$\mathrm{X}$-ray ionizing radiation is used in medical imaging such as radiography, CT scans, radioisotope imaging, etc. Medical radiation is considered a carcinogen for fetuses and children (15).

Ultrasound waves are high-frequency mechanical waves between $2 \mathrm{MHZ}$ and $18 \mathrm{MHZ}$ that are used in diagnostic imaging (ultrasonography). These mechanical waves are non-ionizing and are usually considered to be safe for fetuses, but they have thermal and non-thermal acoustic radiation forces and cavitation effects on cells and tissues (16).

\section{Objectives}

The current research aimed at evaluating the Repeat ultrasound before sex diagnose (RUBSD), Repeat ultrasound during pregnancy (RUDP), Medical ionizing radiation (MIR), pediatric medical ionizing radiation (PMIR), maternal smoking during pregnancy (MSDP), Family history of leukemia (FHL), family history of solid tumors (FHST), children residence place (CRP), background radiation (BR), maternal age of pregnancy (MAP), abortion history (AH), toxic substances (TS), and in vitro fertilization (IVF) baby as possible risk factors for pediatric cancers in order to reduce or eliminate their effects.

\section{Methods}

\subsection{Participants and Procedures}

This cross-sectional descriptive-analytic study was performed in Kurdistan Province in the west of Iran. We studied 103 patients with cancer younger than 14 years old. They were admitted to the oncology ward of Sanandaj Be'sat Hospital.

We conducted the study in 3 sections. The first section was an interview with children's parents using a researcher-made questionnaire whose validity was evaluated by experts, and its reliability was assessed by the testretest method. The second interview was repeated approximately 2 weeks after the first one with the same questionnaire, which included questions about repeated ultrasound before gender determination diagnosis (RUBGD), Repeated ultrasound during pregnancy (RUDP), Maternal ionizing radiation exposure (MIRE), Pediatric medical ionizing radiation (PMIR), Maternal smoking during pregnancy (MSDP), Family history of leukemia (FHL), Children's residence (CRP), Maternal pregnancy age (MPA), Abortion history (AH), IVF baby, and exposure to toxic substances (TS).

\subsection{Data Sources/Measurement}

In the second section of this research, the children's place background radiation dose rate was measured by a survey meter (RDS-110; made in Finland). We measured outdoor and indoor background radiation in cities of Kurdistan province by an RDS-110 serveymeter and calculated the mean background radiation for the cities. Altitude from the sea level in each city was measured by a GPS grid. Annual dose rates (ADR) were calculated for each region according to the following formula (1):

$$
\begin{aligned}
\text { Dose Rate }\left(\frac{\mu S v}{\text { year }}\right)= & \text { Dose Rate }\left(\frac{\mu S v}{h}\right) \\
& \times 24\left(\frac{h}{\text { day }}\right) h \times 365\left(\frac{\text { day }}{\text { year }}\right)
\end{aligned}
$$

In the third part of the research, statistical data were provided from the Kurdistan Registrar's Office (birth information) and the cancer registry of Kurdistan University of Medical Sciences (cancer frequency information).

\subsection{Statistical Analysis}

The statistical analysis was performed with SPSS version 26. The Kolmogorov-Smirnov test was used to evaluate normal and abnormal results. Data analysis used the Chisquare and independent $t$-test. P-value less than 0.05 was considered statistically significant for any test.

Cancer incidence rate in this studied sample size was defined for cities and areas separately. We defined the city and area for data analysis. The cities consisted of urban parts, towns, and villages. Areas consisted of one or more cities placed at the same range in terms of area background radiation (ABR).

Incidence in the studied sample size (ISSS) index rate was calculated per 1000 people. We determined various areas according to the amount of annual dose rates (ADR).

Province regions had a wide distribution of background radiation. We divided the regions into 3 areas in terms of annual background radiation (ABR): less than 1000,1000 - 1100, and more than $1100 \mu$ Sv/year.

We got birth statistics from Sanandaj District Registry. The incidence in the studied sample size at city (ISSSC) and the incidence in the studied sample size at area (ISSSA) indices were calculated per 1000 population. 


\begin{tabular}{|c|c|c|}
\hline Variables & Frequency & Percent \\
\hline \multicolumn{3}{|l|}{ Sex } \\
\hline Male & 54 & 52.4 \\
\hline Female & 49 & 47.6 \\
\hline \multicolumn{3}{|l|}{ Age group } \\
\hline $1-60$ & 49 & 47.6 \\
\hline 61-119 & 34 & 33.0 \\
\hline$>120$ & 20 & 19.4 \\
\hline \multicolumn{3}{|l|}{ Blood groups } \\
\hline A & 48 & 46.6 \\
\hline B & 18 & 17.5 \\
\hline $\mathrm{Ab}$ & 5 & 4.9 \\
\hline $\mathrm{o}$ & 32 & 31.1 \\
\hline \multicolumn{3}{|l|}{$\mathbf{R h}$} \\
\hline+ & 96 & 93.2 \\
\hline- & 7 & 6.8 \\
\hline \multicolumn{3}{|l|}{ Cancer types } \\
\hline All & 59 & 57.3 \\
\hline Aml & 10 & 9.7 \\
\hline Sarcoma & 6 & 5.8 \\
\hline Lymphoma & 7 & 6.8 \\
\hline Neuroblastoma & 3 & 2.9 \\
\hline Brain tumor & 12 & 11.7 \\
\hline Medulloblastoma & 1 & 0.97 \\
\hline $\mathrm{Cml}$ & 1 & 0.97 \\
\hline Wilms tumor & 4 & 3.9 \\
\hline \multicolumn{3}{|l|}{ Cancer groups } \\
\hline Hematologic malignancies & 70 & 68.0 \\
\hline Solid tumors & 33 & 32.0 \\
\hline
\end{tabular}

Abbreviations: all, acute lymphocytic leukemia; aml, acute myeloid leukemia, chronic myeloid leukemia

\section{Results}

The analysis of patient demographic profiles, clinical characteristics, and variables were measured by the questionnaire designed based on the validated surveys with the patient's parents and medical records (Table 1).

The variables were analyzed with SPSS software version v26 and the Student's $t$-test $(\mathrm{T})$ and chi-square $\left(\chi^{2}\right)$ tests were used for data analysis. The Student's $t$-test was used to compare the means, solid tumor, and hematologic malignancies groups for 4 risk factors. The chi-square test was used to evaluate the associations of 6 risk factors and can- cer types. The results of the statistical analysis are shown in Table 2.

In our study, none of the cancerous children were IVF babies. Medical radiation exposure of mother during pregnancy had happened to only one of the mothers who was excluded from the study because she was skeptical.

The cancer incidence rate in larger population sample sizes was higher. The cancer frequency in different cities in the sample size is illustrated in Figure 1.

The measured outdoor and indoor radiations, average background radiation, altitude $(\mathrm{m})$ of cities, and $\operatorname{ABR}(\mu$ sv/y) are presented in Table 3.

The province was divided into areas with $<1000,1000$ - 1100, and $>1100 \mu \mathrm{Sv} /$ year area annual background radiation (ABR). We got birth statistics from Sanandaj District Registry.

The incidence in the studied sample size at city (ISSSC) and that in the studied sample size at area (ISSSA) indices were calculated per 1000 population. The results of measurement and calculations are summarized in Table 4.

According to Table 4, a comparison between the second column (ABR) and the eighth column (ISSSA) shows that incidence in the studied sample size at area (ISSSA) index roughly increased with increasing annual background radiation (ABR). Cities such as Sanandaj due to migration and border cities such as Marivan, Baneh, and Saqez increased in ISSSC index may due to chemical wars.

The increase in background radiation rate was correlated with the ISSSA index in different areas. Therefore, background radiation has a direct association with cancer incidence.

\section{Discussion}

The results showed that cancers were slightly more prevalent in boys (52.4\%) than in girls (47.6\%) with male to female ratios of 1.1. Given that the population of boys is slightly higher than that of girls in our province, it seems to be logical. The results are consistent with Eghbalian et al.'s study (17).

The incidences of pediatric malignancies in different age groups ( 1 - 60, 61 - 120, and > 120 months) were $47.6 \%$, $33 \%$, and $19.4 \%$, respectively. There was a decreasing trend with increasing age. It seems that the declining trend in cancer incidence with increasing age is due to the fading of the role of maternal risk factors. This pattern is consistent with the results of the study by Wiangnon et al. (18).

Ultrasound is a mechanical wave that can be absorbed and transmit energy to tissues. It may have mechanical, thermal, and cavitation effects. The RUBGD and RUDP variables were different for solid tumors and hematologic malignancies, and they were statistically higher in the solid 


\begin{tabular}{|c|c|c|c|}
\hline \multirow{3}{*}{ Variables } & \multicolumn{3}{|c|}{ Statistical Analysis } \\
\hline & \multicolumn{2}{|c|}{ Statistic } & \multirow{2}{*}{ P Value } \\
\hline & $t$-test $(\mathrm{T})$ & Chi-square $\left(\chi^{2}\right)$ & \\
\hline Repeat ultrasound before sex diagnose (RUBSD) & -2.34 & - & 0.023 \\
\hline Repeat ultrasound during pregnancy (RUDP) & -2.21 & - & 0.038 \\
\hline Medical ionizing radiation (MIR) & 2.65 & - & 0.01 \\
\hline Toxic/unusual substances (TS) & 2.20 & - & 0.03 \\
\hline Family history of leukemia (FHL) & - & 36.5 & 0.04 \\
\hline Family history of solid tumors (FHST) & - & 41.3 & 0.01 \\
\hline Children residence place (CRP) & - & 65.38 & $<0.01$ \\
\hline Abortion history (AH) & - & 38.46 & 0.01 \\
\hline Maternal smoking during pregnancy (MSDP) & - & 36.13 & 0.03 \\
\hline Maternal age of pregnancy (MAP) & - & 7.83 & 0.95 \\
\hline
\end{tabular}

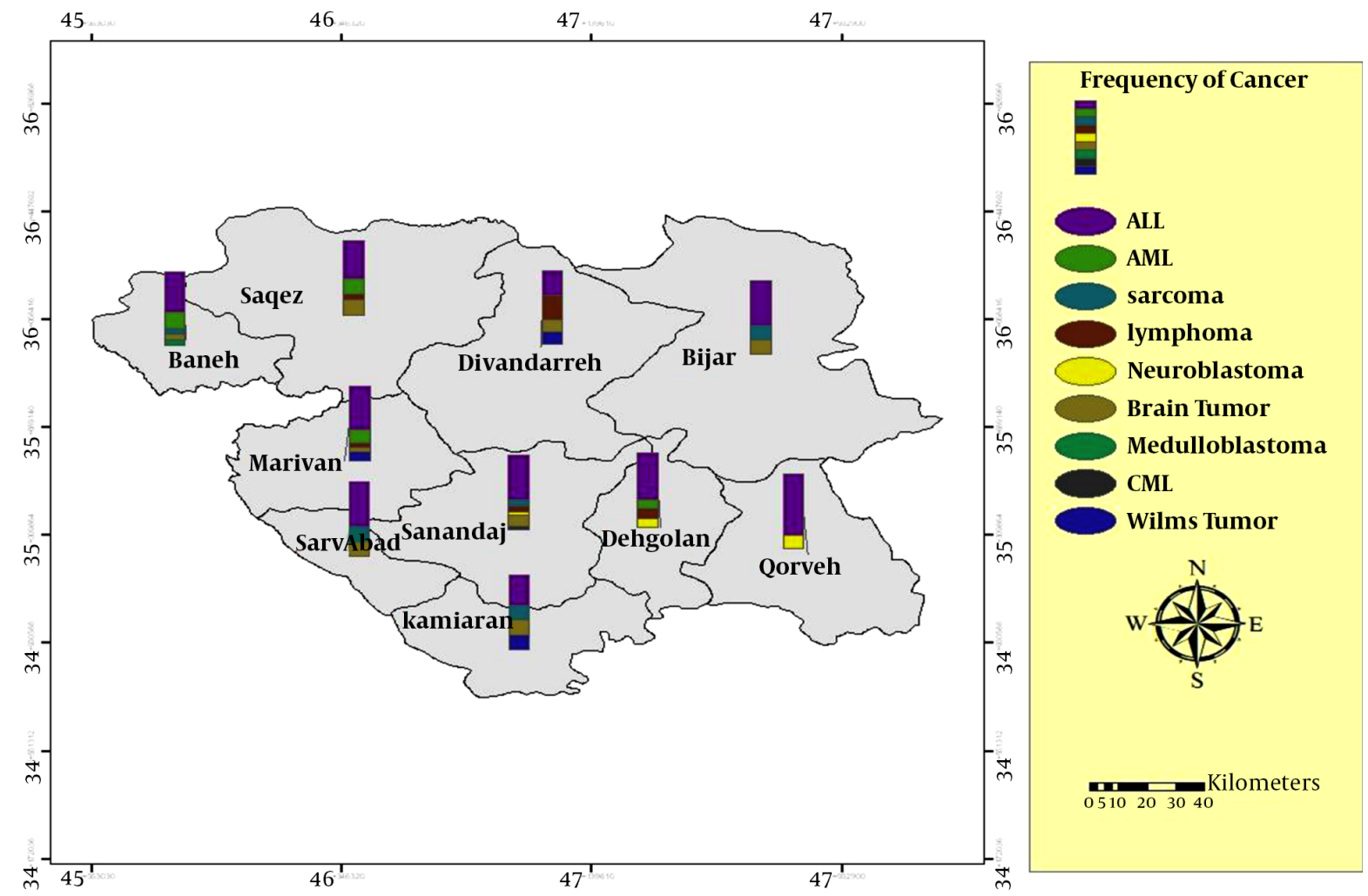




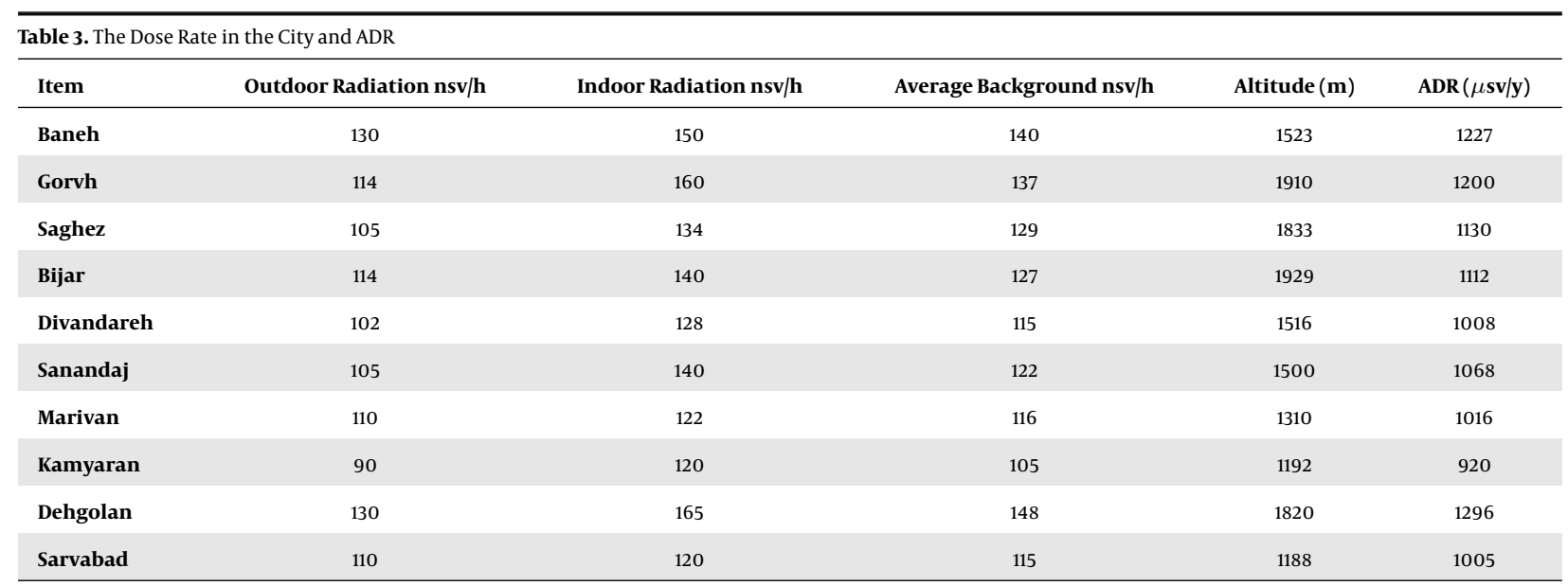

Abbreviation: adr, annual dose rates.

\begin{tabular}{|c|c|c|c|c|c|c|c|}
\hline & $\mathbf{A B R}(\mu \mathbf{s v} / \mathbf{y})$ & City & $\operatorname{ADR}(\mu \mathbf{s v} / \mathbf{y})$ & $\begin{array}{l}\text { Incidence in the } \\
\text { Sample Size }\end{array}$ & Births in Cities & ISSSC Index & ISSSA Index \\
\hline Area 1 & Less than 1000 & Kamyaran & 920 & 5 & 11068 & 0.45 & 0.45 \\
\hline \multirow{4}{*}{ Area 2} & \multirow{4}{*}{$1000-1100$} & Sanandaj & 1064 & 25 & 22979 & 1.08 & \multirow{4}{*}{0.97} \\
\hline & & Divandareh & 1068 & 6 & 10668 & 0.56 & \\
\hline & & Sarvabad & 1005 & 4 & 7962 & 0.50 & \\
\hline & & Marivan & 1016 & 17 & 11921 & 1.42 & \\
\hline \multirow{5}{*}{ Area 3} & \multirow{5}{*}{ Up to 1100} & Qorveh & 1191 & 6 & 11127 & 0.54 & \multirow{5}{*}{1.02} \\
\hline & & Bijar & 1112 & 5 & 5834 & 0.85 & \\
\hline & & Dehgolan & 1296 & 8 & 8215 & 0.98 & \\
\hline & & Baneh & 1227 & 12 & 6637 & 1.8 & \\
\hline & & Saghez & 1120 & 15 & 13067 & 1.14 & \\
\hline
\end{tabular}

Abbreviations: ISSSC, incidence in the studied sample size at city; ISSSA, incidence in the studied sample size at area.

tumors group. This result is consistent with the study conducted by Shu et al. (19), but it contradicts the results of another study by Oppenheim et al. that showed the lack of adverse effects of ultrasound waves (20).

The history of pediatric medical ionizing radiation (PMIR) is an environmental risk factor. The results in our study showed that the mean PMIR in hematologic malignancies is higher than in solid tumors. The results were consistent with the results of the study by Miglioretti et al. (21).

Maternal smoking during pregnancy (MSDP) is a maternal risk factor. The results showed that there is a significant association between MSDP and AML, which is contradicting with the findings of Chunxia et al.'s study (22).

Family history of leukemia (FHL) is a hereditary genetic risk factor. The results showed that there is a significant association between FHL and ALL, which is consistent with the other study conducted by Perrillat et al. (23).

Children's residence place (CRP) is an environmental risk factor. There was a significant association between CRP and ALL. The malignancies were more common in children who lived in basements or on ground floors. Radon gas is a radioactive element that comes from inside the Earth produced by terrestrial materials, rocks, etc. Radon gas could be accumulated in basements, therefore, exposure to radon gas radiation could be directly proportional to residency in lower levels of a building. The results were consistent with a prior study by Raaschou-Nielsen et al. that highlighted the effects of radon gas in ALL (24).

Exposure to toxic substances (TS) could be an environmental risk factor. TS variables were different for solid tumors and hematologic malignancies, and it was statistically higher in the hematologic malignancies group. In line with this result, Poynter et al. emphasized the effects 
of chemical materials in AML type of leukemia (25).

Background radiation (BR) is an environmental risk factor for pediatric cancers. It was directly associated with ALL incidence. Nikkila et al. also showed the effects of BR on malignancy (26).

In this study, in addition to quantitative measurement of radiation, we found promising results by defining incidence in the studied sample size at city (ISSSC) and that in the studied sample size at area (ISSSA) indices in association with BR. The ISSSA roughly increased with increasing background radiation.

\subsection{Conclusions}

The RUBSD and RUDP were statistically higher in the solid tumors group. The TS and PMIR were higher in the hematologic malignancies group. There was a statistically significant relationship between cancer types and FHL, FHST, AH, MSDP, CRP, and BR variables. No statistically significant association was found between different cancer types and MPA, MIRE and IVF baby variables. Pediatric cancers are multifactorial diseases. background radiation is correlated with an increased incidence of pediatric cancers. It seems that increasing ultrasound scans increase the risk of solid tumors in children.

\section{Acknowledgments}

The authors express gratitude Deputy of Research, Kurdistan University of Medical Sciences (grant and ethic code number No. IR.MUK.REC.1396/23) for allocating funds to conduct this study. The authors would like to thank the staff of the Oncology Ward of Be'sat Hospital who helped us to do this research and Mr. Nasrollah Veisi for providing the GIS map.

\section{Footnotes}

\section{Authors' Contribution: $\quad$ B. M. conceptualization,} methodology, data curation. J. A. conceptualization, methodology, Data curation, writing- original draft preparation, investigation. S. D. visualization, investigation, writing- original draft preparation. D. R. software, validation, formal analysis, resources, data curation, writingreviewing and editing. F. E. writing- reviewing and editing.

Conflict of Interests: The authors have no conflict of interests.

Ethical Approval: The ethical approval code was IR.MUK.REC.1396/23.

Funding/Support: This study was supported by a research grant (No: 10953-10) provided by the Deputy of Research, Kurdistan University of Medical Sciences.
Informed Consent: Informed consent was taken from the patient's parents.

\section{References}

1. Ward E, DeSantis C, Robbins A, Kohler B, Jemal A. Childhood and adolescent cancer statistics, 2014. CA Cancer J Clin. 2014;64(2):83-103. doi: 10.3322/caac.21219. [PubMed: 24488779].

2. Khan S, Mir A, Khattak BR, Gull S. Pattern of adulthood hematological malignancies in Khyber Pakhtunkhwa. 12th World Hematologists Congress. London, UK. J Blood Disord Transfus; 2018.

3. Siegel RL, Miller KD, Jemal A. Cancer statistics, 2016. CA Cancer J Clin. 2016;66(1):7-30. doi: 10.3322/caac.21332. [PubMed: 26742998].

4. Seth R, Singh A. Leukemias in children. Indian J Pediatr. 2015;82(9):81724. doi: 10.1007/s12098-015-1695-5. [PubMed: 25680783].

5. Redaelli A, Stephens JM, Laskin BL, Pashos CL, Botteman MF. The burden and outcomes associated with four leukemias: AML, ALL, CLL and CML. Expert Rev Anticancer Ther. 2003;3(3):311-29. doi: 10.1586/14737140.3.3.311. [PubMed: 12820775].

6. Glade Bender JL, Adamson PC, Reid JM, Xu L, Baruchel S, Shaked Y, et al. Phase I trial and pharmacokinetic study of bevacizumab in pediatric patients with refractory solid tumors: a Children's Oncology Group Study. J Clin Oncol. 2008;26(3):399-405. doi: 10.1200/JCO.2007.11.9230. [PubMed: 18202416].

7. Kline NE, Sevier N. Solid tumors in children. $J$ Pediatr Nurs. 2003;18(2):96-102. doi: 10.1053/jpdn.2003.12. [PubMed: 12720206].

8. Hurwitz LM, Yoshizumi T, Reiman RE, Goodman PC, Paulson EK, Frush DP, et al. Radiation dose to the fetus from body MDCT during early gestation. AJR Am J Roentgenol. 2006;186(3):871-6. doi: 10.2214/AJR.04.1915. [PubMed: 16498123].

9. Calisto M, Usoskin I, Rozanov E, Peter T. Influence of galactic cosmic rays on atmospheric composition and dynamics. Atmos Chem Phys. 2011;11(9):4547-56. doi: 10.5194/acp-11-4547-2011.

10. Métivier H. Natural radiation sources, including some lessons for nuclear waste management. Comptes Rendus Physique. 2002;3(7-8):103548. doi: 10.1016/s1631-0705(02)01360-9.

11. Anjos RM, Okuno E, Gomes PRS, Veiga R, Estellita L, Mangia L, et al. Radioecology teaching: evaluation of the background radiation levels from areas with high concentrations of radionuclides in soil. Eur J Phys. 2004;25(2):133-44. doi: 10.1088/0143-0807/25/2/001.

12. Kolarz PM, Filipovic DM, Marinkovic BP. Daily variations of indoor air-ion and radon concentrations. Appl Radiat Isot. 2009;67(11):20627. doi: 10.1016/j.apradiso.2009.07.023. [PubMed:19700332].

13. Linet MS, Kim KP, Rajaraman P. Children's exposure to diagnostic medical radiation and cancer risk: epidemiologic and dosimetric considerations. Pediatr Radiol. 2009;39 Suppl 1:S4-26. doi: 10.1007/s00247-008-1026-3. [PubMed: 19083224]. [PubMed Central: PMC2814780].

14. Ron E. Cancer risks from medical radiation. Health Phys. 2003;85(1):4759. doi: 10.1097/00004032-200307000-00011. [PubMed: 12852471].

15. Kendall G, Little MP, Wakeford R. Numbers and proportions of leukemias in young people and adults induced by radiation of natural origin. Leuk Res. 2011;35(8):1039-43. doi: 10.1016/j.leukres.2011.01.023. [PubMed: 21334745]. [PubMed Central: PMC3998761].

16. Tang J, Guha C, Tome WA. Biological effects induced by non-thermal ultrasound and implications for cancer therapy: A review of the current literature. Technol Cancer Res Treat. 2015;14(2):221-35. doi: 10.7785/tcrt.2012.500407. [PubMed: 24502548].

17. Eghbalian M, Amiri S, Roshanaei G, Esfahani H, Ahmadi M, Assadi Sajadi N. [Common malignancies in children (under 18 years) and its affected factors in Hamedan Province during 1386 to 1395]. J Shahid Sadoughi Univ Med Sci. 2018;25(11):897-906. Persian. 
18. Wiangnon S, Veerakul G, Nuchprayoon I, Seksarn P, Hongeng S, Krutvecho T, et al. Childhood cancer incidence and survival 20032005, Thailand: study from the Thai Pediatric Oncology Group. Asian Pac J Cancer Prev. 2011;12(9):2215-20. [PubMed: 22296359].

19. Shu XO, Jin F, Linet MS, Zheng W, Clemens J, Mills J, et al. Diagnostic X-ray and ultrasound exposure and risk of childhood cancer. BrJ Cancer. 1994;70(3):531-6. doi: 10.1038/bjc.1994.340. [PubMed: 8080742]. [PubMed Central: PMC2033354].

20. Oppenheim BE, Griem ML, Meier P. The effects of diagnostic X-ray exposure on the human fetus: an examination of the evidence. Radiol ogy. 1975;114(3):529-34. doi: 10.1148/114.3.529. [PubMed: 123349].

21. Miglioretti DL, Johnson E, Williams A, Greenlee RT, Weinmann S, Solberg LI, et al. The use of computed tomography in pediatrics and the associated radiation exposure and estimated cancer risk. JAMA Pediatr. 2013;167(8):700-7. doi: 10.1001/jamapediatrics.2013.311. [PubMed 23754213]. [PubMed Central: PMC3936795].

22. Chunxia D, Meifang W, Jianhua Z, Ruijuan Z, Xiue L, Zhuanzhen $Z$, et al. Tobacco smoke exposure and the risk of childhood acute lymphoblastic leukemia and acute myeloid leukemia: A meta-analysis. Medicine (Baltimore). 2019;98(28). e16454. doi:
10.1097/MD.0000000000016454. [PubMed: 31305478]. [PubMed Central: PMC6641792].

23. Perrillat F, Clavel J, Jaussent I, Baruchel A, Leverger G, Nelken B, et al. Family cancer history and risk of childhood acute leukemia (France). Cancer Causes Control. 2001;12(10):935-41. doi: 10.1023/a:1013758114381. [PubMed: 11808713].

24. Raaschou-Nielsen O, Andersen CE, Andersen HP, Gravesen P, Lind M, Schuz J, et al. Domestic radon and childhood cancer in Denmark. Epidemiology. 2008;19(4):536-43. doi: 10.1097/EDE.0b013e318176bfcd. [PubMed: 18552587].

25. Poynter JN, Richardson M, Roesler M, Blair CK, Hirsch B, Nguyen P, et al. Chemical exposures and risk of acute myeloid leukemia and myelodysplastic syndromes in a population-based study. Int J Cancer. 2017;140(1):23-33. doi: 10.1002/ijc.30420. [PubMed: 27603749]. [PubMed Central: PMC5245124].

26. Nikkila A, Erme S, Arvela H, Holmgren O, Raitanen J, Lohi O, et al. Background radiation and childhood leukemia: A nationwide register-based case-control study. Int J Cancer. 2016;139(9):1975-82. doi: 10.1002/ijc.30264. [PubMed: 27405274]. 